\title{
A cerâmica do Sítio Arqueológico Mandaguari, distrito de Floresta do Sul, município de Presidente Prudente/SP
}

\author{
Jean Ítalo de Araújo Cabrera*
}

\begin{abstract}
CABRERA, J.I.A. A cerâmica do Sítio Arqueológico Mandaguari, distrito de Floresta do Sul, município de Presidente Prudente/SP. R. Museu Arq. Etn., 30: 42-54, 2018.

Resumo: Este artigo refere-se à análise do material arqueológico do Sítio Mandaguari encontrado no distrito de Floresta do Sul, no município de Presidente Prudente/SP. Essa avaliação dá conta de que o sítio encontrado é de natureza litocerâmica, sendo que foram encontrados urnas, vasilhames e artefatos líticos polidos e lascados. Pode-se inferir tratar-se de duas populações pré-históricas, uma de coletores/caçadores autores das pontas de projétil e outra de lavradores ceramistas.
\end{abstract}

Palavras-chave: Populações pré-históricas; Líticos; Cerâmicas.

\section{A história de Presidente Prudente: posseiros, colonos e grupos indígenas}

história de Presidente Prudente tem

Linício bem antes de 1917, ainda no século XIX, quando mineiros vieram para a região, em busca de terras favoráveis para a lavoura, depois que as minas de ouro se esgotaram. Nessa região, as terras eram novas, boas e com muita água para as plantações.

De acordo com os dados contidos nos arquivos históricos da Biblioteca Municipal de Presidente Prudente e do Instituto Brasileiro de Geografia e Estatística (IBGE), aqui habitavam índios da etnia Guarani: Xavante e Kaingang (também conhecidos como Coroados). Com a invasão das terras pelos homens brancos, os povos indígenas iniciaram muitas lutas para defender suas

*Professor doutor e pesquisador da Equipe de Arqueologia do Centro de Museologia, Antropologia e Arqueologia (Cemaarq) da Faculdade de Ciências e Tecnologia da Universidade Estadual Paulista (Unesp).

<jeancabrera@terra.com.br> terras, mas foram derrotados e as tribos recuaram para o Mato Grosso e norte do Paraná, sendo suas terras ocupadas por posseiros. José Theodoro de Souza foi um dos primeiros a chegar, por volta de 1850 .

Os primeiros colonizadores que para cá vieram enfrentaram muitas dificuldades, pois não havia nenhuma infraestrutura, como água encanada, energia elétrica, asfalto, supermercados, meios de transportes, lojas.

Segundo Leite (1998), um dos homens conhecidos como colonizador de nossa cidade foi o Coronel Francisco de Paula Goulart. Ele organizou um grupo de companheiros, em setembro de 1917, e veio de Campos Novos do Paranapanema até Indiana, de trem, onde pegou o trem de lastro dos operários da ferrovia e chegou até Memória (hoje Regente Feijó).

De lá, como não havia trem, veio a pé pela Estrada Boiadeira, até chegar ao Alto Tamanduá, perto da estação que estava sendo construída e que seria a de Presidente Prudente (no dia 14 de setembro de 1917). Ele veio tomar posse da fazenda Pirapó-Santo Anastácio, que herdara da família, para tornar-se fazendeiro e 
lotear terras que seriam vendidas para o plantio de café (Leite 1998).

Dois anos depois, quando o trem chegou até Prudente, veio outro fundador, o Coronel José Soares Marcondes, acompanhado do sr. Francisco Cunha, o Picadeiro, que era assim conhecido porque abria picadas na mata, demarcava lotes e abria estradas; fazia, enfim, a divisão das terras para que fossem vendidas. Essas antigas picadas viraram estradas que ligavam as propriedades com a linha férrea. Os lotes foram surgindo na gleba Montalvão, cedida ao Coronel Marcondes pelo sr. Amador Nogueira Cobra para a criação de um núcleo urbano. A Companhia Marcondes de Colonização, Indústria e Comércio criou uma vila, a Vila Marcondes, para abastecer de gêneros, criar escolas e trazer médicos para os novos habitantes do lugar (Leite 1998).

Segundo Abreu (1972), a vinda da ferrovia da região de Sorocaba até o Sudoeste Paulista (nossa região) facilitou a chegada de mais colonos, atraídos pelas terras novas, e, com isso, foram se formando ao longo da linha férrea diversas vilas e povoações, que hoje são cidades, como Martinópolis, Indiana, Regente Feijó, Rancharia, Assis, Presidente Venceslau, Santo Anastácio e outras.

As duas vilas se uniram e toda a povoação recebeu vários nomes. No início, não era Presidente Prudente. O lugarejo antes se chamava Alto Tamanduá. Depois ficou conhecido como Patrimônio do Veado, porque aqui passa o Córrego do Veado. Mas a população não gostava do nome e foi sugerido outro, Patrimônio da Anta. Montalvão foi um terceiro nome, mas que durou pouco. Depois, a nova vila tornou-se Vila Goulart (Abreu 1972). Então, finalmente, a cidade recebeu o nome da estação ferroviária: Presidente Prudente, em homenagem ao presidente Prudente de Morais, nosso primeiro presidente civil, batizada pelo filho dele, quando esteve na cidade para inaugurar o tráfego dos trens.

Segundo Pupim (2008), a primeira lavoura de grande porte na região foi o café, mas em 1929, com a crise mundial, ele decaiu no estado e no país inteiro. Foi então que outra lavoura começou a despontar: o algodão, que além de substituir o café, trouxe indústrias de beneficiamento nacional, como a Matarazzo, e várias estrangeiras, como a Anderson Clayton, para a exportação do produto. Junto com o algodão, começaram a ser plantados também: arroz, feijão, batata e milho, o que favoreceu a criação de novos estabelecimentos comerciais e de beneficiamento na cidade, aumentando os empregos e fazendo a cidade crescer.

Aos poucos, o que era apenas um centro de abastecimento de colonos foi crescendo e a população aumentando, atraindo muita gente de outras vilas, deixando de ser apenas uma cidade, para se transformar em capital regional. As plantações de algodão e a criação de gado exigiam mais indústrias para beneficiar seus produtos (Pupim, 2008).

A população não parou de crescer e, com ela, a cidade de Presidente Prudente, que passou de 54.000 habitantes em 1950 para cerca de $200.000 \mathrm{em}$ apenas 50 anos. Com esse crescimento, as antigas fazendas de café foram se tornando bairros. A antiga fazenda de café dos Bongiovani tornou-se um dos bairros mais conhecidos da cidade. O comércio, a indústria, a criação de bois e cavalos e a posição de entroncamento entre Paraná, Mato Grosso e exterior tornou Presidente Prudente a capital da 10a Região Administrativa do Estado, em 1970. O município de Presidente Prudente possui quatro distritos, além da sede municipal: Montalvão, Floresta do Sul, Eneida e Ameliópolis.

\section{O Sítio Arqueológico Mandaguari}

O Sítio Mandaguari foi diagnosticado a partir de informações dadas pelo proprietário da área, pois, ao preparar a terra de sua propriedade para o plantio, encontrou fragmentos cerâmicos, que reconheceu como sendo de grupo indígena. $\mathrm{O}$ diagnóstico foi realizado pela profa. Dra. Ruth Künzli da Faculdade de Ciências e Tecnologia da Universidade Estadual Paulista (FCT/Unesp), campus de Presidente Prudente, compondo as atividades realizadas pelo Projeto Décima Região, sob sua coordenação. 
O Sítio Arqueológico Mandaguari está localizado no distrito de Floresta do Sul, no município de Presidente Prudente, coordenadas UTM 7568265 N e 0469845 L; sua cota altimétrica aproximada é de 270 metros, estando localizado na carta topográfica DSG/IBGE: SF 22-V-D-IV (Fig. 1), próximo à confluência do Córrego da Onça com o Ribeirão Mandaguari, em área de terraço fluvial, próximo à mata ciliar, com vegetação esparsa e relevo suavemente ondulado em direção ao Córrego do Mandaguari.

Em uma primeira intervenção (1996) na área do Sítio Mandaguari, foram resgatadas, além de duas urnas funerárias, fragmentos de vasilhas, vasilhas cerâmicas inteiras, material ósseo, além de restos de fogueira com vestígios alimentares. De posse desses materiais, foi feita uma triagem no Centro de Museologia, Antropologia e Arqueologia (Cemaarq) da FCT/Unesp, sendo eles limpos, cadastrados e embalados, para posterior análise comparativa com materiais cerâmicos de outros sítios da região. Constatouse que o sítio pertence à Tradição Tupiguarani e ao grupo indígena Guarani.

Os materiais arqueológicos foram encontrados até os 40 centímetros de profundidade, indicando sítios mais recentes, de aproximadamente 500 anos, cujos habitantes provavelmente eram lavradores seminômades, que teriam habitado o local, talvez sucessivamente, construindo cabanas e formando aldeias (Künzli 1998).

As Figs. 2, 3, 4 e 5 mostram a área do sítio na baixa vertente da colina e em meio à plantação de amendoim e milho.

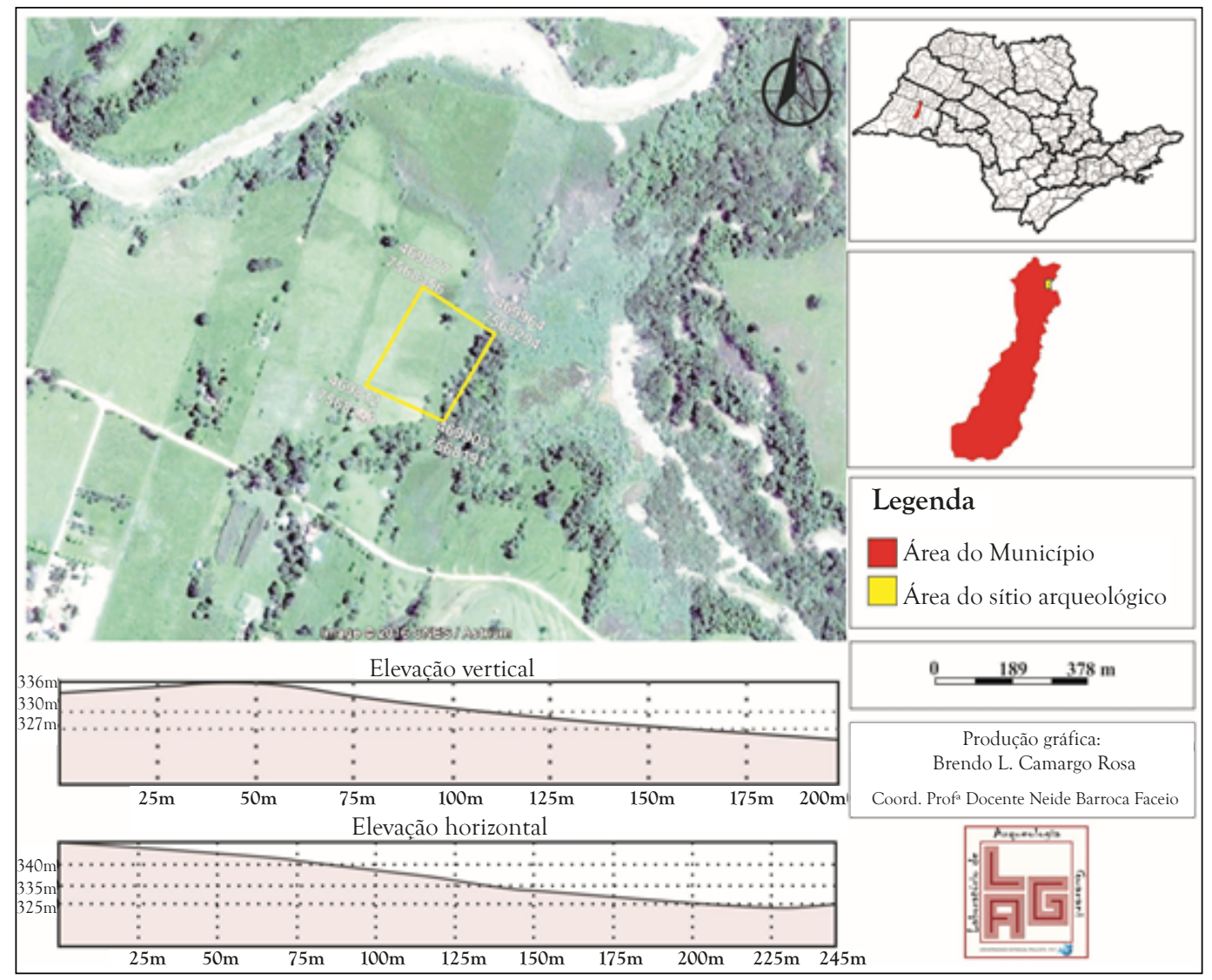

Fig. 1. Localização do Sítio Mandaguari.

Fonte: Cabrera (2016). 


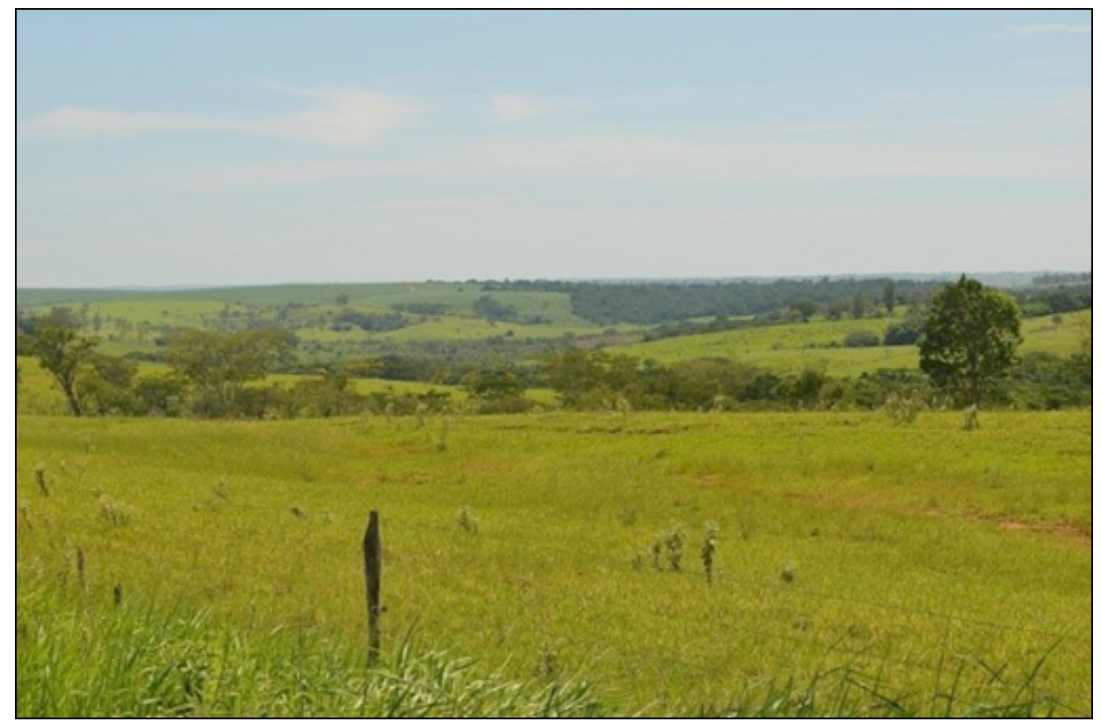

Fig. 2. Localização do sítio na baixa vertente da colina. Fonte: Cemaarq (1996).

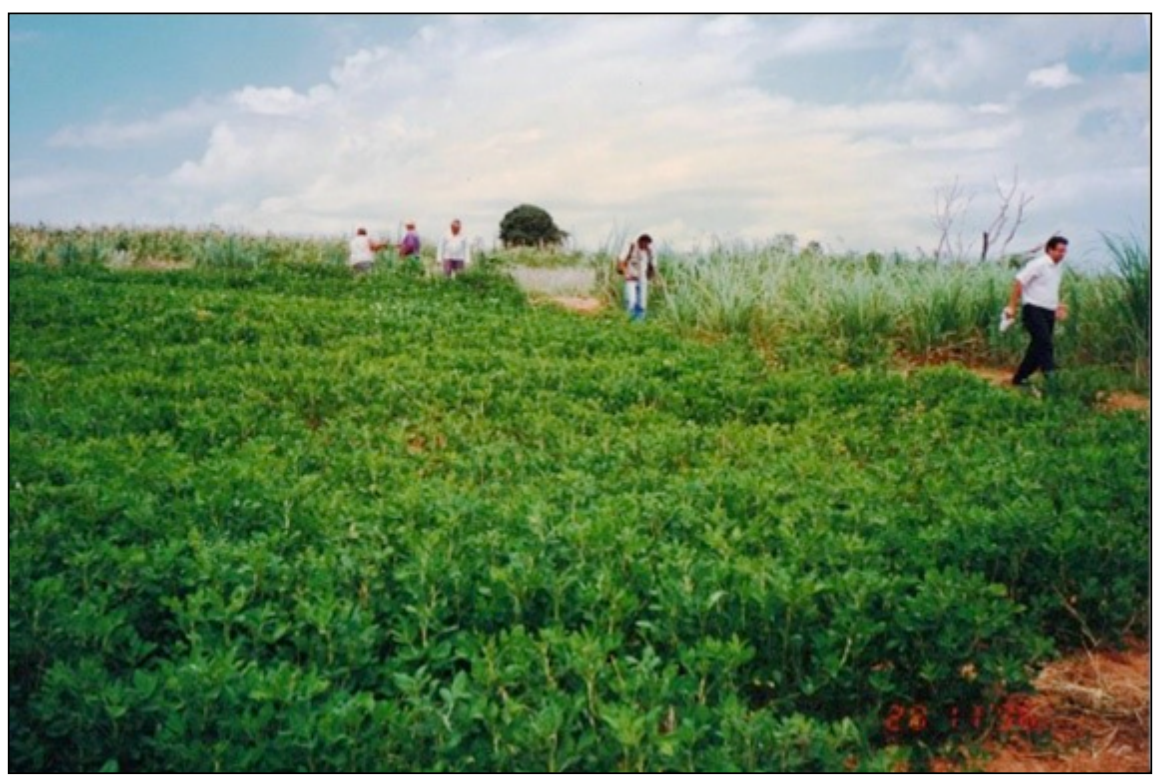

Fig. 3. Cultura de amendoim e milho na área do sítio arqueológico.

Fonte: Cemaarq (1996). 


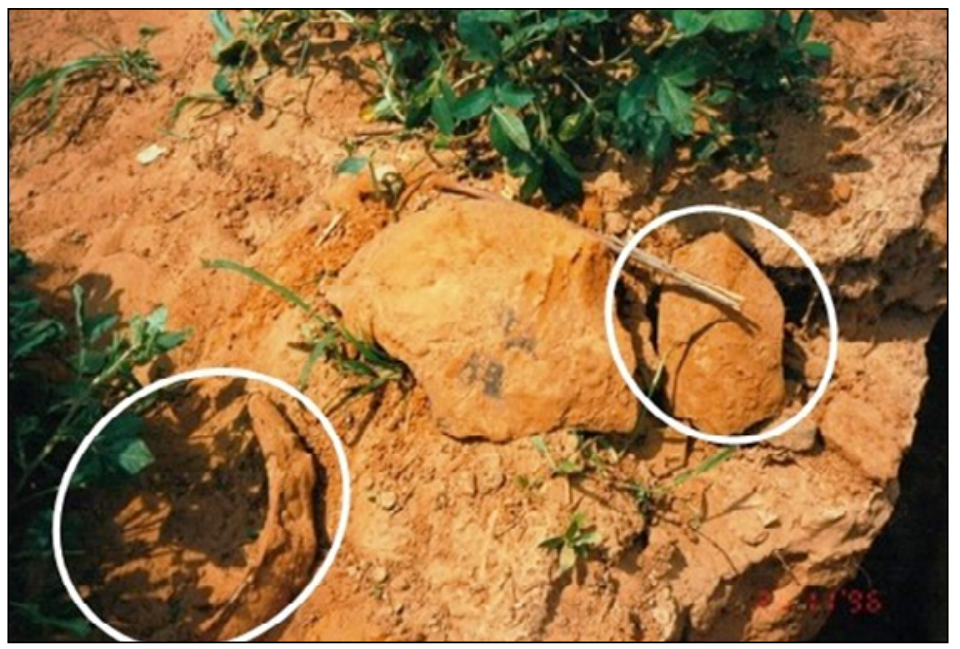

Fig. 4. Bordas de Cambuchi cabaguá evidenciada em meio à cultura de amendoim. Fonte: Cemaarq (1996).

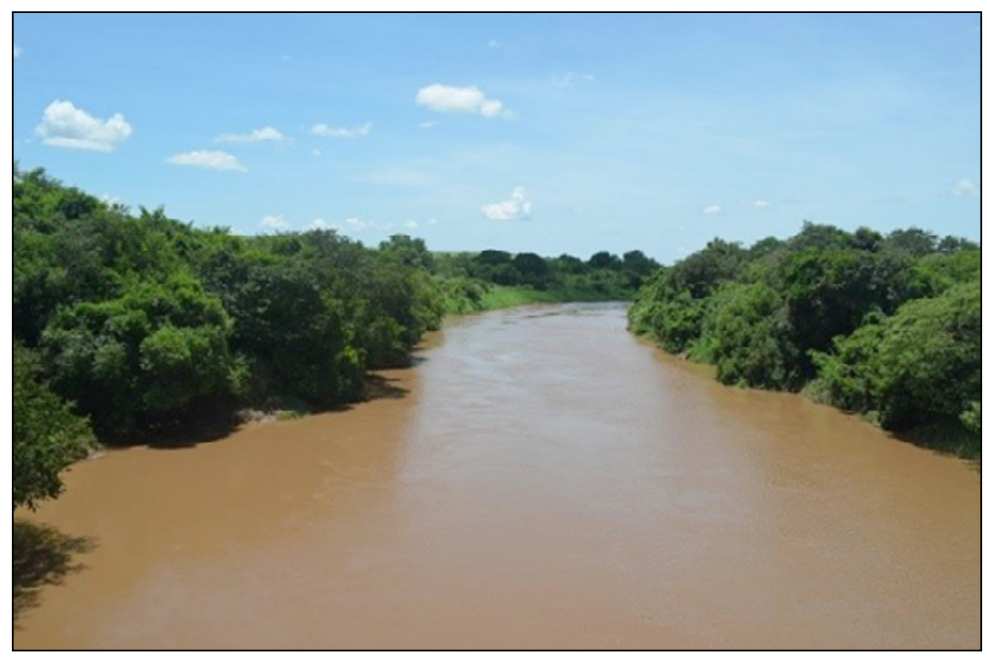

Fig. 5. Córrego Mandaguari.

Fonte: Cemaarq (1996).

Em vistoria realizada pela equipe de Arqueologia do Cemaarq, no ano de 1989, foram encontradas na área do Sítio Arqueológico Mandaguari duas urnas funerárias com adornos (um colar em osso e um tembetá em quartzo), miniatura de vasilha cerâmica e ossos no seu interior, fora da área das manchas pretas. Ainda se verificou, em superfície, a presença de fragmentos de cerâmica. A localização da urna funerária foi na baixa vertente da colina, em meio a uma plantação de amendoim. Pedimos autorização ao dono para poder iniciar o processo de decapagem e retirada da urna em questão (Fig. 6). 


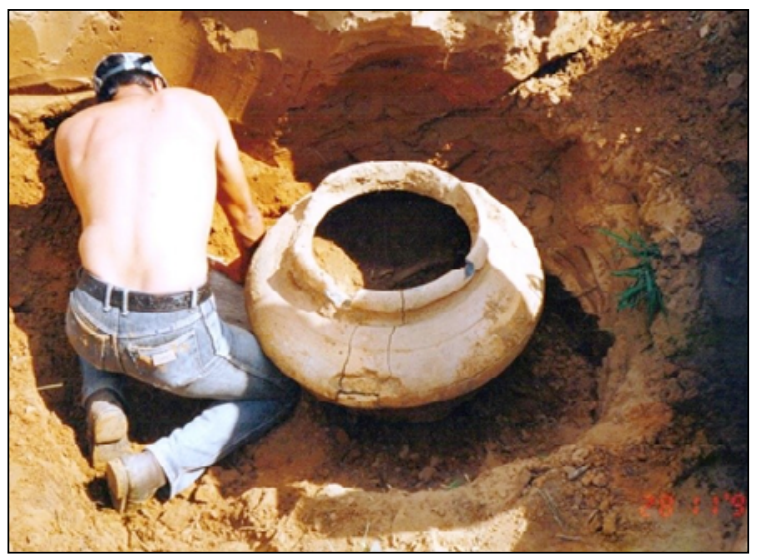

Fig. 6. Processo de evidenciação da urna funerária, por decapagem. Fonte: Cemaarq (1996).

O sítio foi escavado parcialmente, nesse mesmo ano. Em 2010, o local foi revisitado no contexto do "Projeto Geoarqueologia dos Sítios Arqueológicos da Região de Presidente Prudente/SP" com o objetivo de cadastrar o sítio. Nessa ocasião, fragmentos cerâmicos foram observados espalhados em superfície pela área pesquisada.

Os materiais arqueológicos da área do Sítio Mandaguari estão sob a guarda institucional do Cemaarq. Parte da coleção, composta por 118 peças, está acondicionada em reserva técnica e parte exposta em área de visitação.

\section{Os materiais arqueológicos do Sítio Mandaguari}

Os materiais arqueológicos da área do Sítio Mandaguari são compostos por duas urnas funerárias, ossos humanos, dois tembetás, uma miniatura de vaso em cerâmica, um colar e 112 fragmentos de cerâmica, totalizando 118 peças.

Do Sítio Mandaguari, foram estudadas 115 peças cerâmicas, sendo três vasilhas inteiras e 112 fragmentos. Desses fragmentos, 89\% são paredes, $9 \%$ são bordas e 2\% base (Gráfico 1).

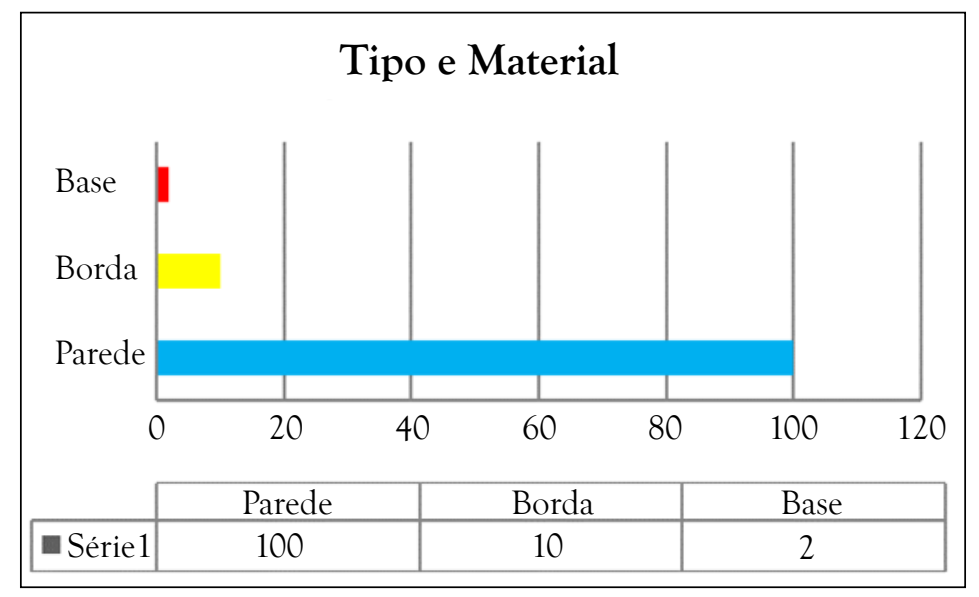

Gráfico 1. Classe das peças cerâmicas do Sítio Arqueológico Mandaguari.

Fonte: Cabrera (2016). 
A técnica de manufatura observada foi a de roletes, cujas espessuras variam de 0,1 a 2,5 centímetros, relacionados com o próprio tamanho das vasilhas. As bases foram preferencialmente confeccionadas por modelagem. A análise da espessura das paredes (Gráfico 2) mostrou que o sítio apresenta vasilhas médias e grandes, em sua maioria.
Foram consideradas miniaturas os recipientes com capacidade de até $200 \mathrm{ml}$ : vasilhas pequenas as peças de $202 \mathrm{ml}$ a 2 litros; médias as peças com capacidade de 2,1 a 10 litros; e vasilhas grandes peças maiores que 10 litros.

São três vasilhas grandes (urnas) e vasilhas de tamanho médio, e uma miniatura (Fig. 7).

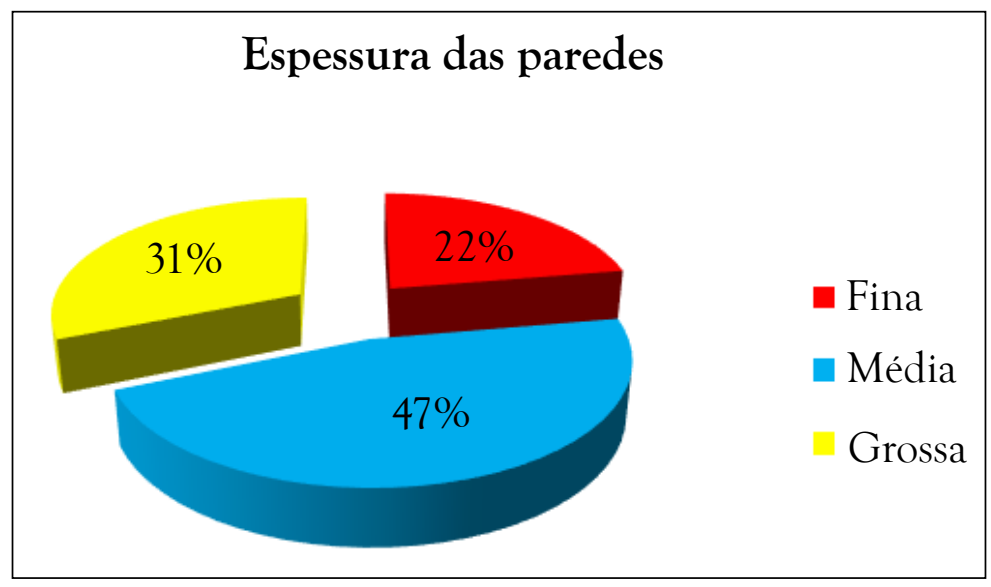

Gráfico 2. Espessura das paredes.

Fonte: Cabrera (2016).

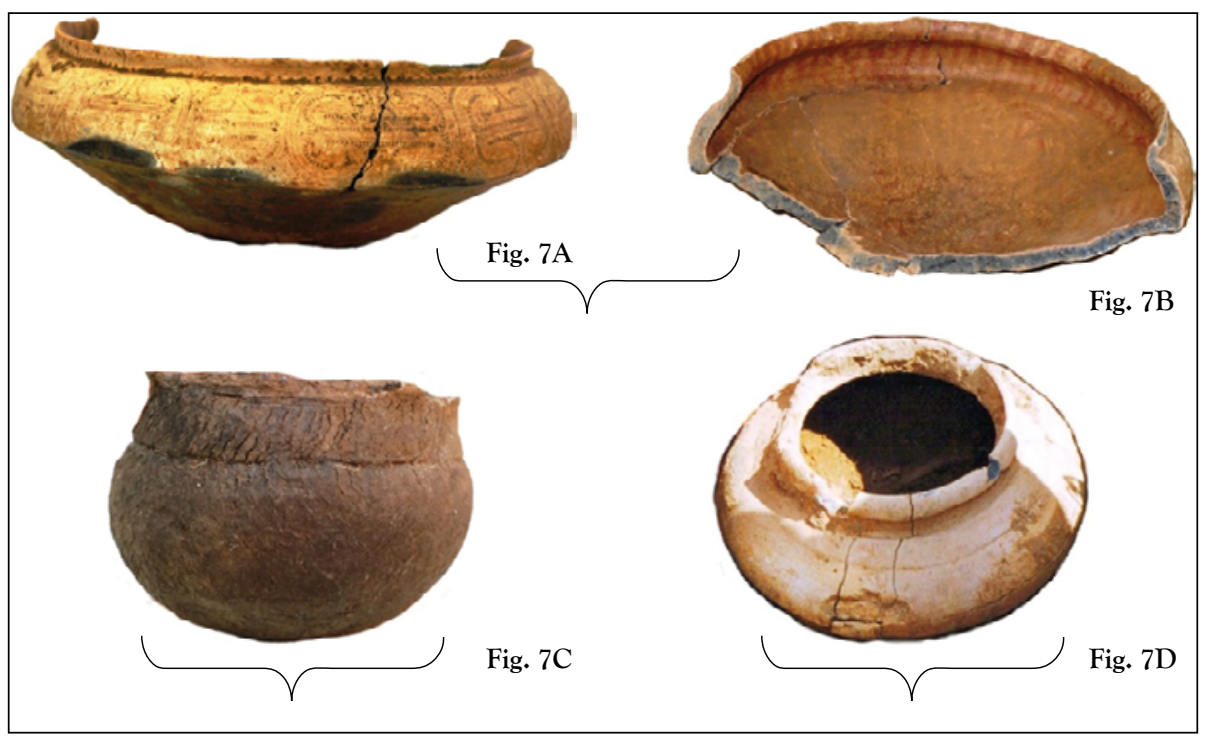

Fig. 7. Vasilhas cerâmicas que compõem a coleção do Sítio Mandaguari.

Fonte: Cabrera (2016). 
A análise do antiplástico baseou-se na metodologia proposta por Faccio $(1992,1998)$. Foram analisados os tipos de antiplásticos encontrados na pasta. Para a confecção das vasilhas Guarani, são comumente encontrados em meio à mistura da pasta o caco moído, o mineral e o carvão. O caco moído é considerado um traço cultural da Tradição Tupiguarani e no Sítio Arqueológico Mandaguari as análises demostraram que $84 \%$ das peças apresentaram caco moído; 9\% caco moído e mineral; e 7\% carvão e mineral (Gráfico 3).

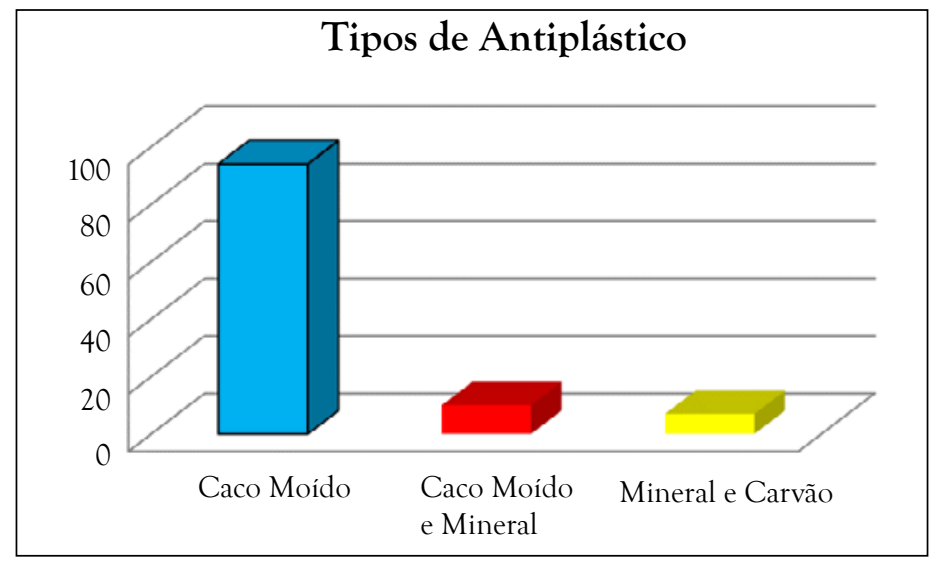

Gráfico 3. Classe das peças cerâmicas do Sítio Arqueológico Mandaguari.

Fonte: Cabrera (2016).

Segundo Faccio (2011), tanto o caco moído quanto o mineral foram utilizados na confecção de vasos guarani de todas as espessuras, e quanto maior a espessura da parede confeccionada, maior a granulação do antiplástico, o que, certamente, se relaciona com a própria estrutura de sustentação do vaso.

Segundo Fontes (2003), para a definição do tipo de queima realizada no material cerâmico, leva-se em consideração a cor das superfícies externa e interna e a cor do núcleo. Esses critérios nos possibilitam avaliar a tecnologia da queima da cerâmica usada pelo grupo indígena.

O tipo de queima encontrado na cerâmica da área do Sítio Arqueológico Mandaguari foi a incompleta e, em menor proporção, a redutora. De maneira geral, os fragmentos cerâmicos apresentam uma boa qualidade de queima.

Quanto aos tipos cerâmicos das 112 peças encontradas na área do Sítio Arqueológico Mandaguari, nota-se uma variabilidade de motivos nas decorações (Gráfico 4) pintadas em 13 peças (Fig. 8A) e nas decorações plásticas, observadas em 15 peças (Fig. 8B). Uma das urnas funerárias, carenada, apresenta decoração pintada na metade superior e corrugada na metade inferior (Fig. 8C). A associação de decoração corrugada com pintada foi também encontrada na cerâmica do Sítio Arqueológico Lagoa São Paulo 2, localizado no município de Presidente Epitácio/SP (Cabrera 2015) e no Sítio Arqueológico Alvim, localizado no município de Pirapozinho/SP (Faccio 1992). Ainda para a área do Sítio Lagoa São Paulo 2, uma das urnas apresentou decoração corrugada na parte superior e escovada na parte inferior (Fig. 8D).

O mais comum na cerâmica guarani carenada é a pintura na parte superior e o liso na parte inferior. Contudo, em menor quantidade são verificadas as variações relatadas para os Sítios Lagoa São Paulo 2 e Alvim (Cabrera 2015; Faccio 1992). 
$\mathrm{Na}$ análise de bordas para reconstituição gráfica da forma dos vasos do Sítio Mandaguari, foram identificados cinco tipos. Verifica-se a presença de bordas direta inclinada interna, extrovertida inclinada interna e extrovertida inclinada externa (Fig. 9).

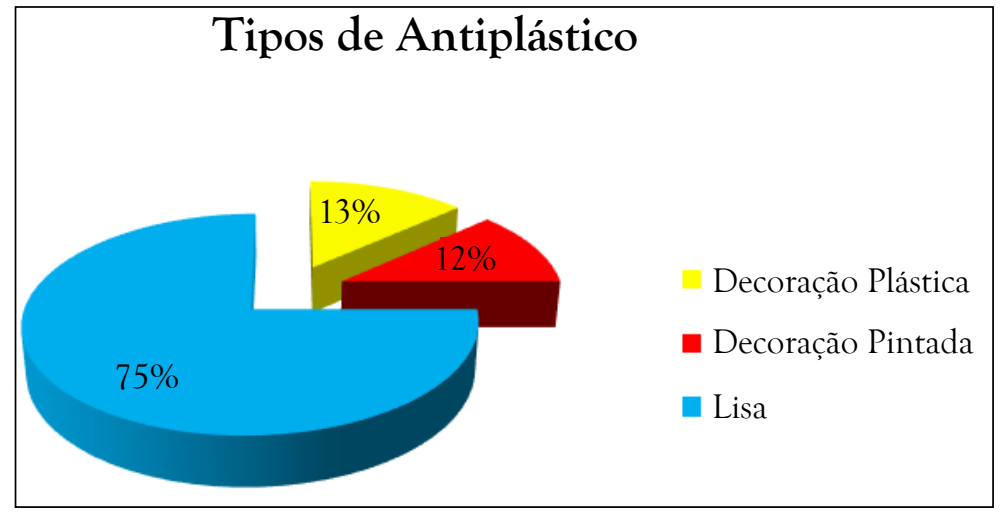

Gráfico 4. Tipos de decoração.

Fonte: Cabrera (2016).

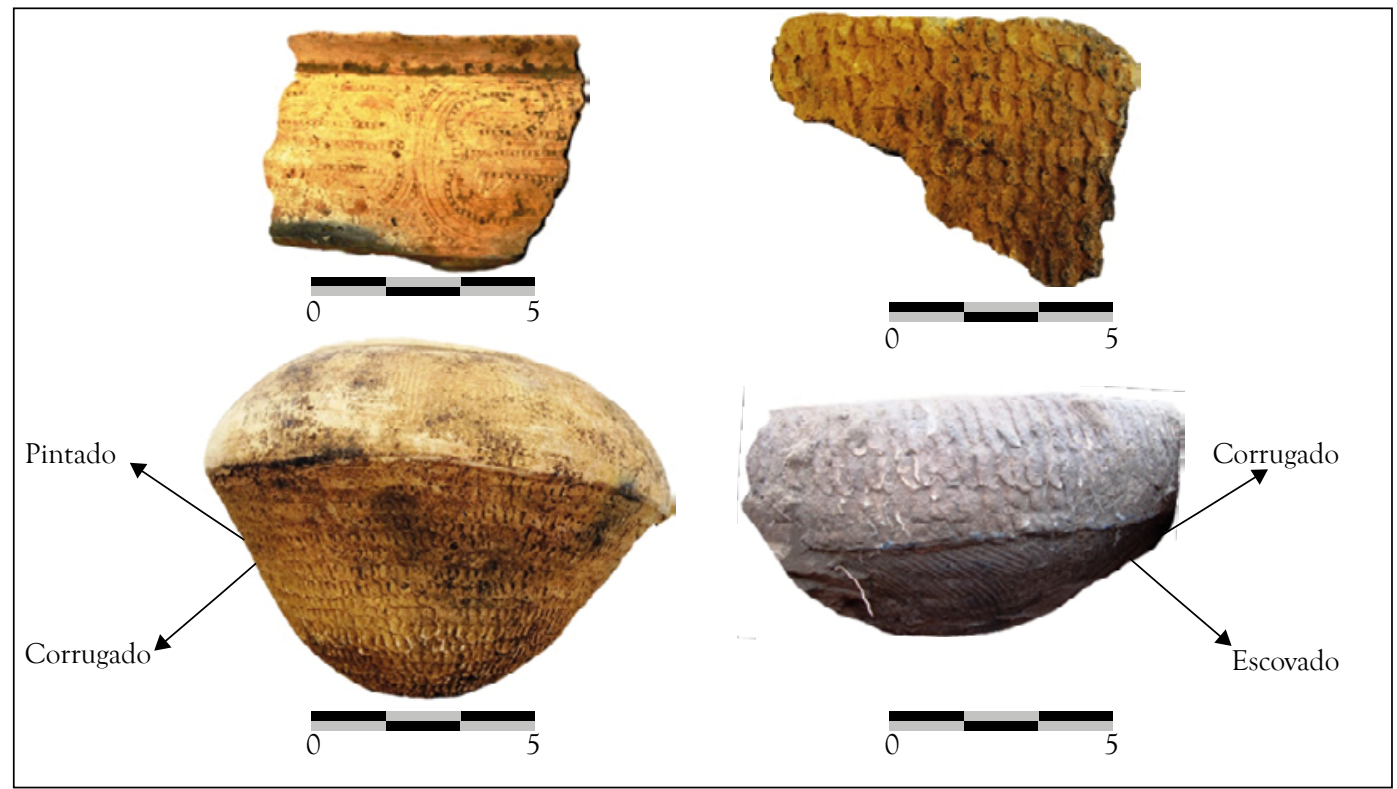

Fig. 8. Tipos de decoração encontradas no acervo da coleção do Sítio Mandaguari.

Fonte: Cabrera (2016). 


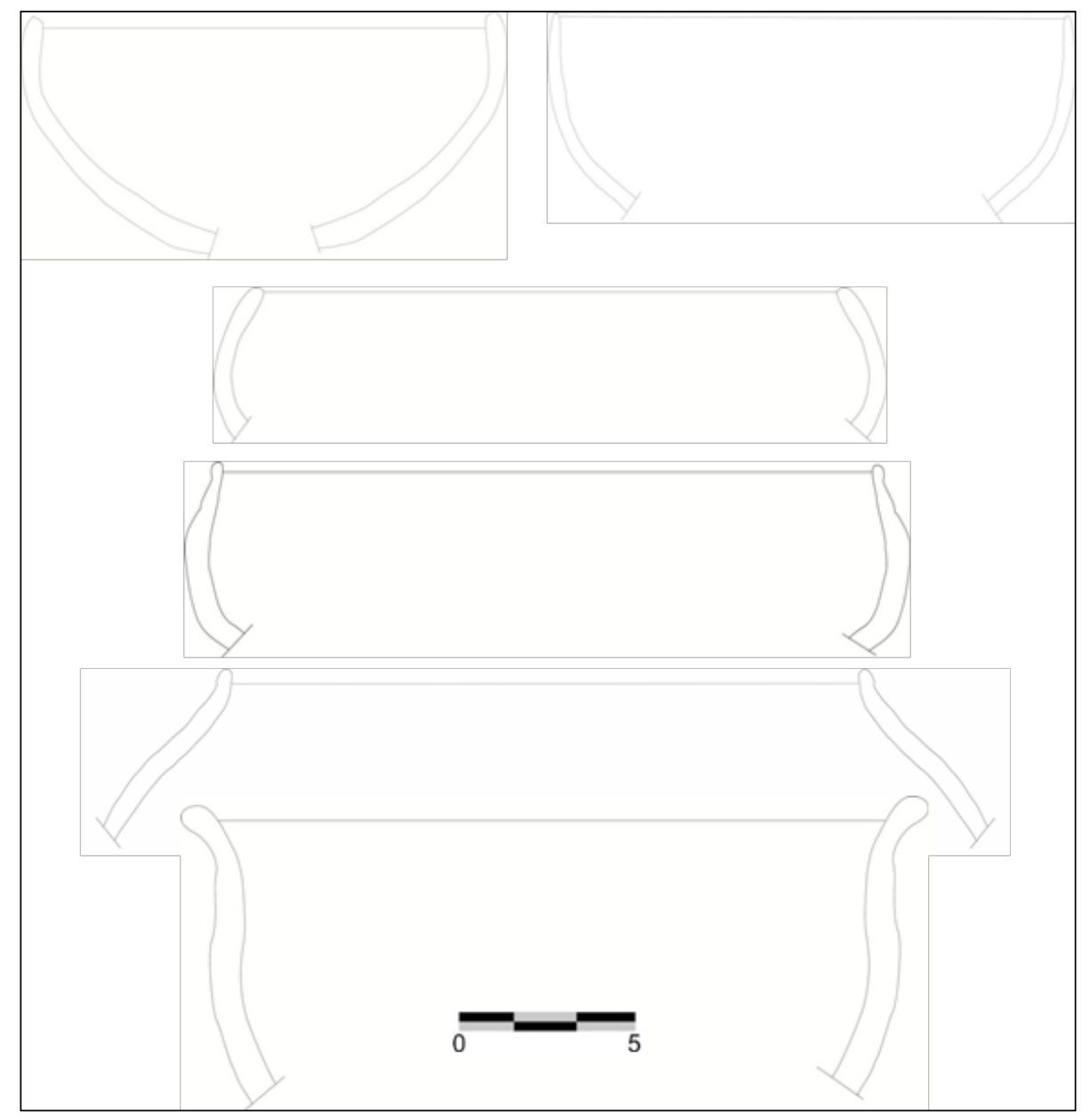

Fig. 9. Reconstituições da forma de bordas do Sítio Mandaguari.

Fonte: Cabrera (2016).

Segundo Faccio (2011), embora a reconstrução gráfica da forma da vasilha seja feita a partir da análise das bordas, essa tarefa é um tanto quanto difícil e polêmica, principalmente quando se trata de fragmentos de borda de tamanho pequeno, porque, nesse caso, a reconstrução gráfica da forma da vasilha não é totalmente confiável. Para as peças do Sítio Mandaguari, foram utilizadas bordas com tamanho que possibilitaram reconhecer a forma. As bordas selecionadas para sua reconstituição gráfica passaram por processo de digitalização, por meio de mesa digitalizadora e foram reconstituídas utilizando os recursos do software Corel Draw X8.

A Urna 1, apresentada na Fig. 10, continha ossos humanos em processo de decomposição, onde puderam ser reconhecidos um fêmur, partes de costelas e um conjunto de dentes (Fig. 11), além de um tembetá de quartzo (Fig. 12), uma lâmina de machado polida (Fig. 13), um pequeno vasilhame de cerâmica (Fig. 14) e, também, um colar feito de ossos (Fig. 15) (cuja reconstituição foi feita com base na disposição da peça dentro da urna). 


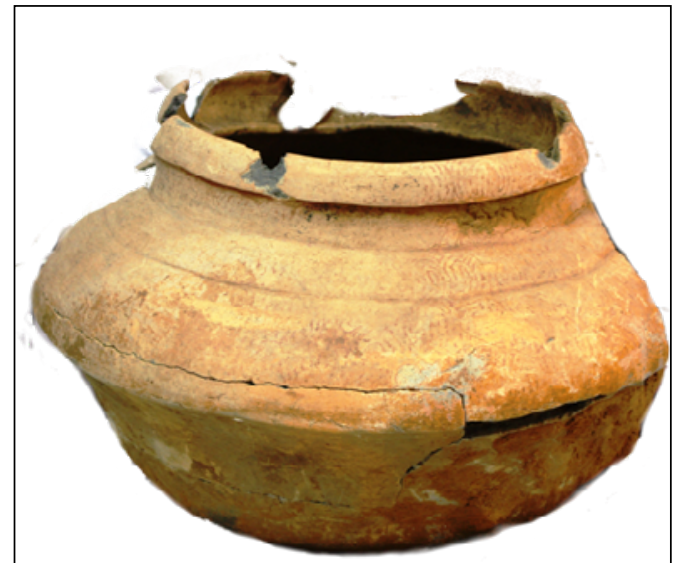

Fig. 10. Urna resgatada do Sítio Mandaguari. Fonte: Cabrera (2016).

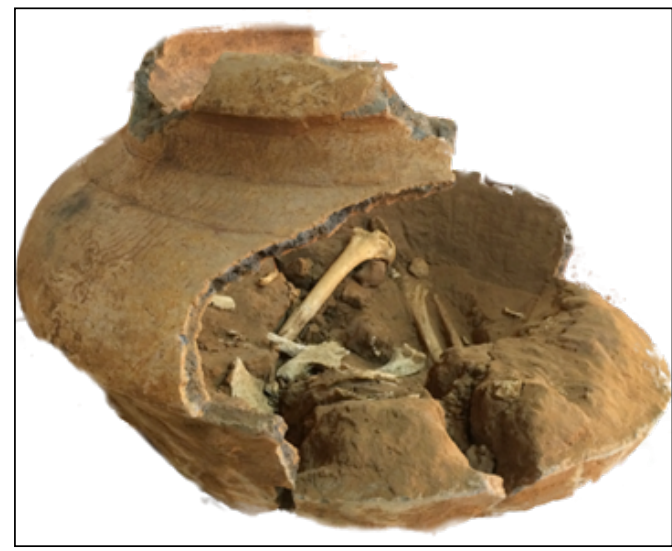

Fig. 11. Material ósseo encontrado dentro de uma urna funerária do Sítio Arqueológico Mandaguari.

Fonte: Cabrera (2016).

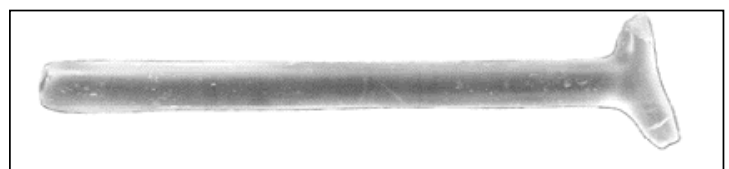

Fig. 12. Tembetá de quartzo encontrado dentro de uma urna funerária do Sítio Arqueológico Mandaguari.

Fonte: Cabrera (2016).

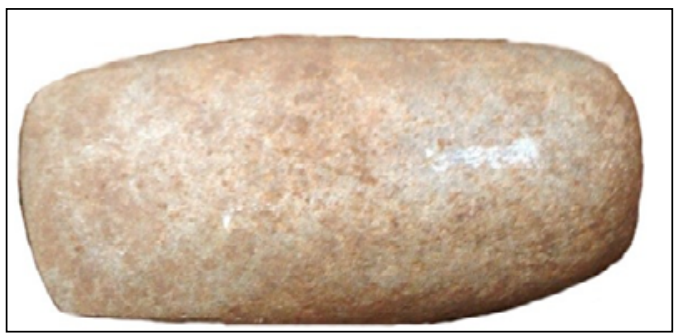

Fig. 13. Lâmina de machado polida encontrada em urna funerária do Sítio Arqueológico Mandaguari.

Fonte: Cabrera (2016).

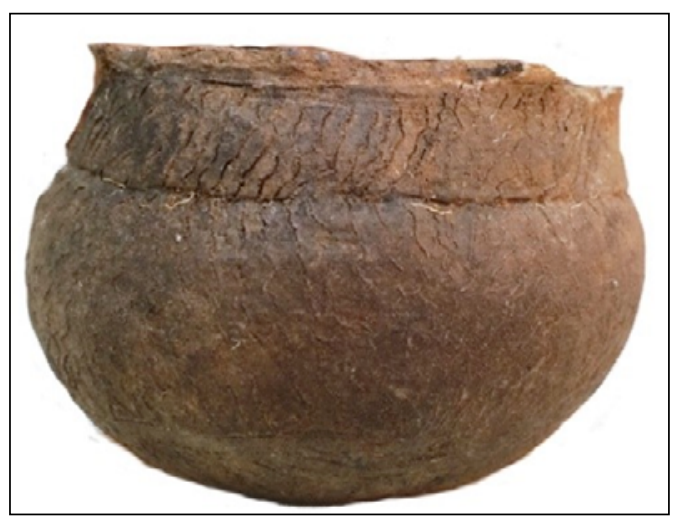

Fig. 14. Miniatura de vasilha cerâmica encontrada em urna funerária do Sítio Arqueológico Mandaguari.

Fonte: Cabrera (2016).

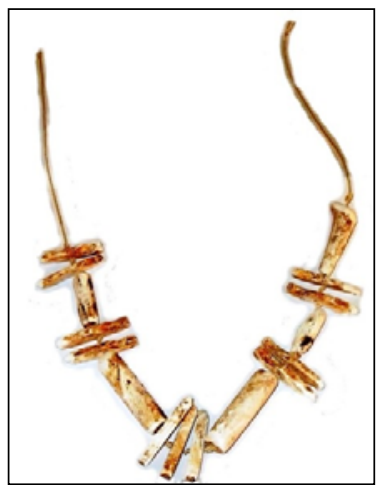

Fig. 15. Colar feito de ossos encontrado em urna funerária do Sítio Arqueológico Mandaguari.

Fonte: Cabrera (2016). 
No interior da urna 2, havia: ossos em avançado estado de decomposição, não sendo possível identificar suas formas; um fragmento de tembetá de quartzo (Fig. 16); e uma miniatura de cerâmica semelhante à urna 1.

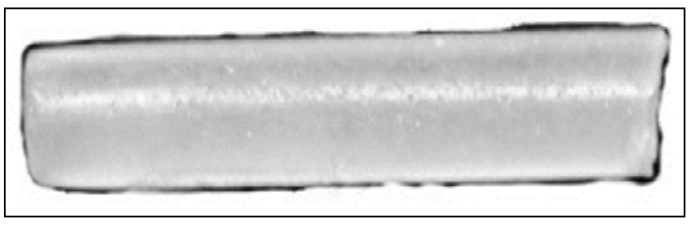

Fig. 16. Fragmento de tembetá de quartzo do Sítio Arqueológico Mandaguari.

Fonte: Cabrera (2016).

As características dos materiais cerâmicos e líticos do Sítio Arqueológico Mandaguari são semelhantes aos de outros sítios Guarani encontrados nas áreas próximas dos Rios Paraná e Paranapanema, margem paulista, como é o caso dos Sítios Alvim, Pernilongo e Aguinha (Faccio 1992, 1998).

\section{Considerações}

Os grupos Guarani apresentam resiliência no padrão de assentamento e na forma de produção cerâmica. A ocupação de áreas de terraço é constatada ao longo dos grandes rios, como o Paraná e o Paranapanema, bem como ao longo de seus afluentes na área do Oeste paulista. Na produção da cerâmica notam-se as mesmas formas e tipos de decoração.

$\mathrm{O}$ aldeamento Guarani denominado Sítio Arqueológico Mandaguari apresenta quatro manchas pretas, cerâmica com antiplástico caco moído, formas carenadas e pintura vermelha e preta sobre engobo branco. $\mathrm{Na}$ área desse aldeamento ainda foram encontrados enterramentos em urnas funerárias, tembetás em quartzo e um colar em osso.

O sítio está localizado em uma área próxima da confluência de dois corpos d'água, de terra fértil, favorável para coleta de matéria-prima destinada à confecção dos vasos de argila. Essas características de localização são comuns a sítios Guarani do baixo Paranapanema paulista, como se podem citar o Sítio Célia Maria, do município de Marabá Paulista (Pereira 2011) e Alves, de Piraju/SP (Morais 1981) respectivamente.

Não foi evidenciado nenhum tipo de material lítico lascado, mas é provável que eles manuseassem tal material, pois no interior de um dos sepultamentos foi encontrado um tembetá em quartzo polido e uma lâmina de machado polida. Registraram-se, também, no leito do Córrego Mandaguari, seixos em silexito e arenito silicificado com boa qualidade para o lascamento.

A pesquisa realizada na área do Sítio Mandaguari teve por objetivo salvaguardar os materiais arqueológicos de superfície ou urnas funerárias parcialmente expostas. Nesse sentido, o sítio ainda apresenta potencial para resgate.

CABRERA, J.I.A. Mandaguari Archaeological Site's ceramics, Floresta do Sul district, municipality of Presidente Prudente/SP. R. Museu Arq. Etn. 30: 42-54, 2018.

Abstract: This article refers to the analysis of Mandaguari Site's archaeological material found in Floresta do Sul district, municipality of Presidente Prudente/SP. The evaluation will allow us to conclude that the found site is lito-ceramic in nature, as polished and chipped lithic urns, containers and artifacts were found there. We can infer that there were two prehistoric populations at the location, one of collectors/hunters, makers of the projectile points, and the other of pottery making farmers.

Keywords: Prehistoric populations; Lithic; Ceramic. 


\section{Referências bibliográficas}

Abreu, D. 1972. Formação histórica de uma cidade pioneira paulista: Presidente Prudente. Publicação da Faculdade de Filosofia, Ciências e Letras, Presidente Prudente.

Cabrera, J.I.A. 2015. O espaço ocupado pelo homem pré-histórico no Oeste paulista: o caso do Sítio Arqueológico Lagoa São Paulo - 02 no município de Presidente Epitácio/SP. Tese de Doutorado. Universidade Estadual Paulista, Presidente Prudente.

Cabrera, J.I.A. 2016. Diários de campo e relatórios de atividades referentes à análise dos sítios do Projeto Décima Região Administrativa. (Relatório final). Cemaarq, Presidente Prudente.

Faccio, N.B. 1992. Estudo do Sítio Arqueológico Alvim no contexto do Projeto Paranapanema. Dissertação de mestrado. Universidade de São Paulo, São Paulo.

Faccio, N.B. 1998. Arqueologia dos Cenários das Ocupações Horticultoras da Capivara, Baixo Paranapanema-SP. Tese de doutorado. Universidade de São Paulo, São Paulo.

Faccio, N.B. 2011. Arqueologia Guarani na Área do Projeto Paranapanema: estudo dos Sítios de Iepêl $S P$. Tese de Livre-Docência. Universidade de São Paulo, São Paulo.
Fontes, M.A.F. 2003. A cerâmica pré-histórica da área arqueológica do Seridó/RN. Dissertação de mestrado. Universidade Federal de Pernambuco, Recife.

Künzli, R. 1987. Arqueologia regional: primeiros resultados das pesquisas realizadas na área de Presidente Prudente/SP, Revista do Museu 32: 223-247.

Künzli, R. 1998. Relatórios de 1 a 10: Projeto de Salvamento Arqueológico de Porto Primaveral $S P$. (Relatório final). Cesp/Fundacte-Unesp, Presidente Prudente.

Leite, J.F. 1998. A ocupação do Pontal do Paranapanema. Hucitec; Fundação Unesp, São Paulo.

Morais, J.L. 1981. Projeto Paranapanema: avaliação e perspectivas. Revista de Antropologia, 24: 141-151.

Pereira, D. L.T. 2011. Arqueologia guarani na bacia do rio Santo Anastácio-SP: estudo do sítio Célia Maria. Tese de doutorado. Universidade de São Paulo, São Paulo.

Pupim, R. G. 2008. Cidade e Território do Oeste Paulista: mobilidade e modernidade nos processors de construção e reconfiguração do urbano. Dissertação de mestrado. Universidade de São Paulo, São Carlos. 